\title{
The Effect of Intensive Short-Term Dynamic Psychotherapy on Marital Conflicts and Interpersonal Processing of Married Women with Emotional Divorce
}

\author{
Azam Parisuz ${ }^{1}$, Samaneh Najarpourian ${ }^{2 *}$, Kourosh Mohammadi ${ }^{3}$ \\ 1. PHD student of Counseling, Faculty of Human Sciences, University of Hormozgan, Bandar Abbas, Iran. \\ Tel: +98-9038031892, Email: parisuz.azam@gmail.com \\ 2. Assistant Professor of Counseling, Department of Counseling, Research Center of Educational \& \\ Behavioral Sciences, University of Hormozgan, Bandar Abbas, Iran. Tel: +98-9177314044, Email: \\ najarpourian@hormozgan.ac.ir (*Corresponding Author) \\ 3. Assistant Professor of Psychology, Department of Counseling, Faculty of Human Sciences, University of \\ Hormozgan., Bandar Abbas, Iran, Email: Mohammadi.km@gmail.com
}

\begin{abstract}
Emotional divorce is accompanied by growing negative emotions and it affects couples' relationship. Marital conflicts and interpersonal processing are among the important elements of a marital relationship. The present study is aimed at investigating the effect of Intensive Short-Term Dynamic Psychotherapy (ISTDP) on marital conflict and interpersonal processing of married women with emotional divorce in the city of Tehran. The method of the study was quasi-experimental with pretest-posttest and follow-up with control group design. For this purpose, 40 women who were emotionally divorce were selected using convenience sampling and randomly assigned to control and experimental groups. Experimental group received ISTDP. Results revealed that the experimental group showed reduced conflict levels $(\mathrm{F}=43.93, \mathrm{p}<0.01)$ and increased interpersonal processing $(\mathrm{F}=85.43, \mathrm{p}<0.01)$. Therefore, ISTDP reduces negative emotions and consequent conflicts in marital relationships and improving couples' interpersonal processing.

Keywords: Interpersonal processing, Marital conflict, ISTDP, Couple therapy, Emotional divorce.
\end{abstract}

\section{Introduction}

Marriage is one of the most lasting relationships between man and woman. It assigns, and in return, renders specific rights and duties upon individuals respectively, relieves couples' needs and with itself brings feelings of safety, prosperity, peace, and happiness. However, this relationship is sometimes disturbed, causing a separation of the family and members within it (Haviland, Prins, McBride, \& Walrath, 2013). In extreme cases, conflicts lead to divorce and the relationship between couples reaches a dead end. Divorce comes in various forms. In its formal, legal form, the relationship is ruptured, meaning that the couple has no duties/rights to serve for the other. On the other hand, it can take up a hidden, latent form in which the marital and familial relationship becomes factitious and shatters from within (Sahebihagh, Khorshidi, Atri, \& Jafarabadi, 2017).

In those communities in which there are strict traditions for practicing marriage, or which the economy is unstable, there is a lower tendency towards official divorce, especially on the side of women, but there is a considerable number of cases of emotional divorce. In Iran, society regards divorce as an obscene phenomenon for women (Sahebihagh et al., 2017). Furthermore, divorce inflicts more severe social and economic problems upon women, which can lead to an increased number of forced marriages among this population. Hence, emotional divorce can happen more often with women (Hashemi \& Homayuni, 2017). According to different statistical reports, there is an increasing number of reported divorces in Iran, estimated to occur around 11 
to 12 percent. The 99852 cases of divorce reported in 2008 reached an intriguing number of 142841 cases in 2012 (Statistical Center of Iran, 2012). Alongside these numbers, there is another, and yet bigger, hidden estimation of emotional divorce in Iran. It can be estimated that the number of emotional divorces is two times bigger than its official counterpart.

In an emotional divorce, the couple stays together because of needs or other necessities, but their relationship is far from constructive (Sahebihagh et al., 2017). Couples continue living together, but they are far less driven to each other and their level of trust in one another abates gradually or it fully diminishes (Kaslow, 2010). Hence, emotional divorce is the stage in a married couple's life where positive feelings and emotions such as love, friendship and couples' attraction to each other are scaled-down and these emotions are replaced by negative ones; anger, rage, hatred, and disappointment. Characteristics which previously used to connect couples, now lose their worth and mutual, constructive relationships will be debased (Hashemi \& Homayuni, 2017). Emotional divorce often occurs unwantedly and in a latent manner and as it continues to augment, couples feel more distanced and separated from each other, feeling even more enraged and disappointed with each other (Hashemi \& Homayuni, 2017).

One of the essential predictors of emotional divorce is marital conflicts and a lack of problem-solving abilities (Lalzadeh, Asghari Ebrahimabad, \& Hesarsorkhi, 2015). Marital conflicts can endanger healthy communication between couples and family members, leading to a reduction of a constructive mutual relationship between them. Parallel to love in a romantic relationship, conflict develops unavoidably, making its way through the marriage. More specifically, conflict occurs when one's actions cross those of the other's, and as they get closer to another, this crossing escalates. Conflict among family members contaminates the sense of oneness in the family. In more extreme cases, conflict engenders split, aggression and defiance among family members and will gradually shatter the pillars of the family (Haratian, Janbozorgi, \& Agah, 2015).

Interpersonal processing, another determinant of marital life quality (Naderi Nobandegani, 2015), which influences marriages considerably, refers to such characteristics as reflexive thinking about oneself, relationship with the other, observing the partner's viewpoint and understanding mutual interactions (Reid, Dalton, Laderoute, Doell, \& Nguyen, 2006). Interpersonal processing, a relatively new concept in the field of martial studies, does not mean to have a great deal of information about one or their spouse; rather it highlights the fact that in a relationship, individuals influence each other mutually and their interactions lead to a somehow unique dynamic. In the presence of interpersonal processing, one attempts to direct their attention at the influences their transactions leave on others' transactions and on how they develop a mutual dynamic in-between (Miller, 2008).

Increasing marriage dissatisfaction and divorce rates on the one hand, and the ever-growing demands for enrichment programs that improve marital satisfaction, on the other hand, highlights the gap, and couples' needs, for required psychological interventions. There are several approaches for increasing intimacy, and as a consequent, reducing emotional divorce among couples, each of which adheres to their own philosophical background and their understanding of mankind and the concept of family in their theoretical and practical framework, and consequently, they have formed their unique way of dealing with such issues as marital conflict and intimacy. One of these approaches is psychodynamic psychotherapy. Derived from the 
Freudian theory of psychoanalysis, psychodynamic psychotherapy considers opposite forces of humans' psyche as the source of their motivations, conflicts, and the fountain for human beings' anxiety and distress. Despite its apparent focus on the patient's growth, psychoanalysis emphasizes an individual's interaction with her family. Based on psychoanalytic theory, Davanloo (1999) has developed an intensive short-term dynamic psychotherapy (ISTDP). ISTDP helps patients regulate their anxiety against their defenses to enable them to face feelings they have been avoiding to encounter (Frederickson, Messina, \& Grecucci, 2018). ISTDP especially emphasizes the therapeutic relationship and disclosure as well. Therapist's active stance and the techniques he/she employs will help the client get to know, and in touch with, his feelings and thoughts in favor of better, improved mental health (Jarareh \& Talepasand, 2011).

Dew (2008) showed that training communication styles in solving problems and conflicts influence young couples' marital satisfaction. Sharif, Soleimani, Mani, and Keshavarzi (2013) studied the effect of conflict management skills on marital satisfaction, confirming its efficacy. Rahmani, Salehi, and Rezae (2009) reported similarly that reduced anxiety symptoms in psychodynamic and pharmacotherapy groups, but the intensity of anxiety showed a more considerable reduction. Yet another study by Jarareh and Talepasand (2011) indicated that ISTDP interventions on tactical defenses proved effective in increasing marital satisfaction. Haidari and Alahyari (2012) found that there is a significant difference between posttest average scores of marital conflicts and its subscales among female participants in comparison with the pretest scores. Faramarzi, Azadfallah, Rasoolzadeh-Tabatabai, and Shokry-Shirvani (2012) reported that ISTDP is a reliable therapeutic model for improved gastric symptoms and conflict management in patients suffering gastric hypersensitivity. Khorianian, Heidari, Tabibi, and Aghamohammadian (2013) showed that ISTDP intervention decreases depression symptoms and increases individuals' emotional expression.

According to theoretical frameworks and relevant studies, emotional distress is accompanied by negative emotions such as aggression, rage, disappointment, and uncertainty. Emotional divorce influences couples interactions and as a result of that, marital conflicts escalate and personal processing decreases. ISTDP couple therapy can decrease couples marital conflicts and increase interpersonal processing. Accordingly, the most important issue in the present study is to see what effects ISTDP can have on emotionally divorced married women's conflict and interpersonal processing. Hence, two specific hypotheses of the study are as follows: First hypothesis: ISTDP effects on interpersonal processing of married women with emotional divorce.

Second hypothesis: ISTDP effects on marital conflict of married women with emotional divorce.

\section{Material and Methods}

The method of the study was quasi-experimental, pretest-posttest and follow up with the control group. Samples were selected using convenience sampling and were randomly assigned. After matching, participants were randomly assigned to control and experimental groups. The sample included 40 married women with emotional divorce (20 control and 20 experimental groups). A set of prerequisites such as emotional divorce (score of 8 in emotional divorce questionnaire), participant's willing consent, no more than 1 session absence in the training 
session, no determining mental or physical disorders, perfect sanity to participate in the study, and not being in other concurrent counseling and/or therapy services were considered for participation in the study.

\section{Tools}

Marital Conflict - Revised: Barati and Sanaee's (1379) Marital Conflict - Revised (MCQ-R) (Sanaei \& Barati, 2000) was used to measure marital conflict level. It has 54 items with 5-Point Likert Scale which has eight dimensions for evaluating marital conflict, including: decreased coordination, decreased sexual intercourse, increased emotional reactions, increased children's protection, increased personal relations with his/her own kindred, decreased family relations with the spouse's kindred, and friends, separate finances from each other, decreased effective relation. Bahari, Fatehizadeh, Ahmadi, Molavi, and Bahrami (2010) reported 0.80 Cronbach's alpha for this questionnaire. Haratian et al. (2015) reported 0.89 Cronbach's alpha for the questionnaire. Cronbach's alpha was 0.95 in current study.

Interpersonal Processing Scale: Reid and Zahradnik quoted by Miller (2008)) developed Interpersonal Processing Scale (IPS) in the laboratory of York University for two purposes which are increasing couples' awareness of their spouse's thoughts and feelings, and secondly the Couples' level of understanding of cognitive and emotional reactions in the process of the relationship with their spouse. It has a 6-Point Likert Scale including 1, strongly disagree to 6, strongly agree. Scoring ranges from 20 to 120 and the higher the score, the higher the interpersonal processing level. The scale measures three dimensions of interpersonal processing include the Reflexive thinking, Absorption of viewpoint, and the Concurrent use of reflexive thinking and absorption of viewpoints. Diaconescu quoted by Reid, Doell, Dalton, and Ahmad (2008) reported 0.88 Cronbach's alpha for the questionnaire. Coefficient alpha was 0.86 in the present study.

Emotional divorce questionnaire: To identify married women with emotional divorce, Gottman (2008) emotional divorce questionnaire was employed. It is a 'Yes' or 'No' 24 item questionnaire, which score for 'yes' is 1 and for 'no' is zero. The score ranges from 0-24, higher scores indicate higher levels of emotional divorce. The cut-off point of the questionnaire is 8; it means 8 'yes' answers conclude emotional divorce. Gottman (2008) reported 0.70 Cronbach's alpha for the questionnaire. Cronbach's alpha was 0.83 in present study..

Intervention: Davanloo (1999) ISTDP was implemented for the interventions of the present study, and the following is a summary of 8 sessions of the interventions:

\begin{tabular}{|l|l|}
\hline $\begin{array}{l}\text { First } \\
\text { session }\end{array}$ & $\begin{array}{l}\text { Introduction to the counselor and therapy; trial therapy, exploring developmental, medical and social } \\
\text { background of married women participating in the study. }\end{array}$ \\
\hline $\begin{array}{l}\text { Second } \\
\text { session }\end{array}$ & $\begin{array}{l}\text { Exploring their marriages and the sources of their resistance; dynamic exploration in their marriage } \\
\text { (investigating sexual conflicts); zooming in on married women's feelings (cognitive, physical and } \\
\text { motor aspects); reactivating and reinforcing resistance; focusing attention on signs of transference. }\end{array}$ \\
\hline $\begin{array}{l}\text { Third } \\
\text { session }\end{array}$ & $\begin{array}{l}\text { Escalating the challenge level; tackling resistance head-on. Examining physiological signs of anxiety; } \\
\text { analyzing triangle of conflict and triangle of the person. }\end{array}$ \\
\hline $\begin{array}{l}\text { Fourth } \\
\text { session }\end{array}$ & $\begin{array}{l}\text { Challenging and engaging resistance in transference; penetrating deep feelings of guilt; brief } \\
\text { exploration of the unconscious; exploring their relationship with their spouse and their own parents. }\end{array}$ \\
\hline Fifth & More direct challenging, engagement and pressure; more dynamic exploration and touching \\
\hline
\end{tabular}


The Effect of Intensive Short-Term Dynamic Psychotherapy on Marital Conflicts and Interpersonal Processing...

\begin{tabular}{|l|l|}
\hline session & $\begin{array}{l}\text { transferential feelings, exploring unconscious setbacks and frustrations, more and more digging into the } \\
\text { past and its unconscious effect on participants' lives. }\end{array}$ \\
\hline $\begin{array}{l}\text { Sixth } \\
\text { session }\end{array}$ & $\begin{array}{l}\text { Digging through deep, unconscious feelings of guilt; analysis of transference; penetrating through a } \\
\text { wide range of painful feelings; questioning married women's schemata. }\end{array}$ \\
\hline $\begin{array}{l}\text { Seventh } \\
\text { session }\end{array}$ & Deeper analysis of transference; re-evaluating resistances; examining and analyzing new schemata. \\
\hline $\begin{array}{l}\text { Eighth } \\
\text { session }\end{array}$ & Conclusion of therapeutic analyses, evaluation of therapeutic meetings, farewell and termination. \\
\hline
\end{tabular}

Participants: Participants were selected from among married women visiting 2 counseling centers in Tehran and once their consent was earned, they were asked to fill out the Gottman (2008) questionnaire. Forty women out of ninety-four clients, who met emotional divorce criteria, were chosen. Then, they were assigned to control and experimental groups randomly. Before applying the intervention, a pretest was carried out on both groups and then the experimental group received ISTDP, whereas the control group received no intervention. After the intervention, posttest was carried out on both groups. The follow-up was carried out three months after posttest. Data was collected and analyzed using SPSS version 22 on descriptive and inferential levels. Descriptive statistics included mean and standard deviation and inferential statistics included repeated measure.

Ethics considerations: The subject and the aim of the study were clarified to the participants in the first session, and those participants' consent that was willing to take part in the study was acquired. They were apprised of the fact that the study would cause them no harm of any kind. The participants, were alerted that they could terminate their participation in the study at any given stage of the study, without being inflicted with any consequences. Participants were not asked to provide their name or other identifiable information about them.

\section{Results}

Demographical data of the study indicated that the average age of the participants was 35.92, age of marriage was 26.90, and duration of marriage was reported 9.02. Seven people did not have children (17.50 percent), 14 people had one child (35 percent), 16 individuals had 2 children (40 percent) and three participants had 3 children ( 7.50 percent). Twenty three people were housewives (57.50 percent) and 17 of them were employed (42.50 percent).

Findings also indicated average emotional divorce in the experimental group to be 19.45 and in the control group, it was 19.80. Therefore, women in both groups were experiencing high levels of emotional divorce. Table 1 presents participants' descriptive statistic (mean and SD) based on phase of study and group for interpersonal processing and marital conflict variables.

Table 1. Descriptive Results of interpersonal processing and marital conflict of control and experimental groups in pretest and posttest

\begin{tabular}{|l|l|l|l|l|l|l|l|l|}
\hline \multirow{2}{*}{ Group } & \multicolumn{4}{|c|}{ Marital Conflict } & \multicolumn{2}{l|}{ Interpersonal Processing } & \multirow{2}{*}{ Emotional Divorce } \\
\cline { 2 - 9 } & & pretest & posttest & & pretest & posttest & follow-up & \\
\hline \multirow{3}{*}{ Experimental } & $\mathrm{M}$ & 212.8 & 128.35 & 154.20 & 57.75 & 92.65 & 85.60 & 19.45 \\
\cline { 2 - 9 } & SD & 24.57 & 21.43 & 25.62 & 7.85 & 7.94 & 7.58 & 3.18 \\
\hline & $\mathrm{M}$ & 212.35 & 213.60 & 212.05 & 57.26 & 57.9 & 57.25 & 19.8 \\
\cline { 2 - 8 } & SD & 22.62 & 22.24 & 22.17 & 7.09 & 7.41 & 6.31 & 2.41 \\
\hline
\end{tabular}


Repeated measure analysis was applied to analyze data. As a parametric test, $\mathrm{F}$ requires certain statistical prerequisites. They include normal distribution, equality and homogeneity of variances. Box's M test shows the homogeneity of variances (table 2), Leven test shows the equality of variances (table 3 ) and normally test was presented in table 4. According to table 4, data were normally distributed.

Table 2. Box's M test results for interpersonal processing and marital conflict variables

\begin{tabular}{|l|l|l|l|l|l|}
\hline & Box's M & F & Df1 & Df2 & P \\
\hline Marital Conflict & 12.99 & 1.97 & 6 & $10462 / 189$ & 0.178 \\
\hline Interpersonal Processing & 9.767 & 1.488 & 6 & $10462 / 18$ & 0.065 \\
\hline
\end{tabular}

Table 3. Leven test results for interpersonal processing and marital conflict variables

\begin{tabular}{|l|l|l|l|l|l|}
\hline Index & Phase & F & Df1 & Df2 & P \\
\hline Marital Conflict & pretest & 0.002 & 1 & 38 & 0.966 \\
\cline { 2 - 6 } & posttest & 0.356 & 1 & 38 & 0.554 \\
\cline { 2 - 6 } & follow-up & 0.108 & 1 & 38 & 0.744 \\
\hline \multirow{4}{*}{ Interpersonal Processing } & pretest & 0.074 & 1 & 38 & 0.787 \\
\cline { 2 - 6 } & posttest & 0.001 & 1 & 38 & 0.977 \\
\cline { 2 - 6 } & follow-up & 0.265 & 1 & 38 & 0.609 \\
\hline
\end{tabular}

Table 4. Kolmogorov-Smirnov Test Results for interpersonal processing and marital conflict variables

\begin{tabular}{|l|l|l|l|l|l|}
\hline \multirow{2}{*}{ Group } & \multicolumn{2}{l|}{ Experiment } & Control \\
\cline { 3 - 6 } & Z & Z & Z & P \\
\hline \multirow{4}{*}{ Marital Conflict } & pretest & 0.085 & 0.200 & 0.128 & 0.200 \\
\cline { 2 - 6 } & posttest & 0.128 & 0.200 & 0.149 & 0.200 \\
\cline { 2 - 6 } & follow-up & 0.119 & 0.200 & 0.142 & 0.200 \\
\hline \multirow{3}{*}{ Interpersonal Processing } & pretest & 0.138 & 0.200 & 0.111 & 0.200 \\
\cline { 2 - 6 } & posttest & 0.083 & 0.200 & 0.135 & 0.200 \\
\cline { 2 - 6 } & follow-up & 0.171 & 0.128 & 0.125 & 0.200 \\
\hline
\end{tabular}

First hypothesis: ISTDP effects interpersonal processing of married women with emotional divorce. The result of repeated measure related to first hypothesis was presented in tale 5 .

Table 5. Repeated Measures Test Results for First hypothesis

\begin{tabular}{|l|l|l|l|l|l|l|l|}
\hline Source & SS & DF & MS & F & P & Partial Eta Squared & Observed Power \\
\hline Time & 6995.717 & 2 & 3497.858 & 1158.50 & 0.01 & 0.968 & 1.00 \\
\hline Time * Group & 6632.15 & 2 & 3316.075 & 1098.293 & 0.01 & 0.967 & 1.00 \\
\hline Error & 229.467 & 76 & 3.019 & & & & \\
\hline Group & 13483.2 & 1 & 13483.2 & 85.437 & 0.01 & 0.692 & 1.00 \\
\hline Error & 5996.933 & 38 & 157.814 & & & & \\
\hline
\end{tabular}

Mauchly's test of sphericity results showed sphericity for interpersonal processing ( $\mathrm{p} 0.163$, $\mathrm{W}=0.906, \mathrm{df}=2$ ). Repeated measure for the interpersonal processing showed a significant main effect of time and interaction effect $(\mathrm{p}<0.001)$. This finding means that interpersonal processing has changed from pretest to follow-up. The table also shows that the group effect (within-group effects) $(\mathrm{F}=85.43, \mathrm{p}<0.01)$, was significant. In other words, there is a significant difference 
The Effect of Intensive Short-Term Dynamic Psychotherapy on Marital Conflicts and Interpersonal Processing...

between control and experimental group on the interpersonal processing level in three stages (pretest, posttest, and follow-up). It can be inferred that ISTDP has influenced interpersonal processing of married women with emotional divorce, increasing interpersonal processing.

Second hypothesis: ISTDP effects marital conflict of married women with emotional divorce. The result of repeated measure related to second hypothesis was presented in tale 6 .

Table 6. Repeated Measures Test Results for Second hypothesis

\begin{tabular}{|l|l|l|l|l|l|l|l|}
\hline Source & SS & DF & MS & F & P & Partial Eta Squared & Observed Power \\
\hline Time & 36382.467 & 1.442 & 25236.336 & 748.773 & 0.01 & 0,952 & 1.00 \\
\hline Time * Group & 38526.647 & 1.442 & 26723.5 & 792.897 & 0.01 & 0.954 & 1.00 \\
\hline Error & 1864.4 & 54.783 & 33.704 & & & & \\
\hline Group & 68784.408 & 1 & 68784.408 & 43.932 & 0.01 & 0.536 & 1.00 \\
\hline Error & 59496.85 & 38 & 1565.707 & & & & \\
\hline
\end{tabular}

Mauchly's test of sphericity proved negative for marital conflict hypothesis $(p<0.01 . \mathrm{Df}=2$, $\mathrm{W}=0.613$ ), therefore we will use epsilon correction, Greenhouse-Geisser correction, for df. Repeated measure showed a significant main effect of time $(\mathrm{p}<0.001)$ and a significant interaction effect $(\mathrm{p}<0.001)$. The significant main effect of time means marital conflict has changed from pretest to follow-up. Also, the interaction effect (within-group effects) was significant $(\mathrm{F}=43.93, \mathrm{p}<0.01)$. It can be concluded that there is a significant difference between control and experimental groups in marital conflict in three stages (pretest, posttest, and followup). Hence, ISTDP influences marital conflict of married women with emotional divorce.

\section{Discussion}

The present study investigated the effect of ISTDP on marital conflict and interpersonal processing of married women with emotional divorce in Tehran. Results showed the significant effect of the intervention in reducing conflict and increasing interpersonal processing. The current results are in line with previous studies (Faramarzi et al., 2012; Haidari \& Alahyari, 2012; Jarareh \& Talepasand, 2011; Khorianian et al., 2013; Rahmani et al., 2009)These studies found that ISTDP can reduce and increase marital conflict and interpersonal processing respectively. Also, the current results are in line with Dew (2008), and Sharif et al. (2013), studies in which training communication skills and conflict management can decrease marital conflict and increase interpersonal communication skills.

Studies, as well as clinical examples, suggest that in today's world, individuals experience serious difficulties in initiating intimate relationships and keeping them, solving marital conflicts and meeting their partner's expectation and needs. Developing and maintaining intimate relationships, and fulfilling a spouse's emotional and mental needs is a learnable skill; an art. Not only one needs to have a peaceful, healthy mind, but also they require a logical mindset and a set of skills to perform certain duties. Increased marital conflicts cause individuals to avoid facing deep feelings, negative thoughts and emotions such as conflict and aggression or to ignore them (Sharif et al., 2013).

In an emotional divorce, spouses are unconsciously urged to distance from each other, developing those negative emotions and affects. ISTDP seeks, as well as focuses on, disclosure. Therapist's proactive stance in using ISTDP techniques helps individuals unravel the depth of 
their feelings and thoughts, to get in touch with them (Ghorbani, Watson, Sarmast, \& Chen, 2018).

Increased conflict and reduced interpersonal processing in married women with emotional divorce lead to a decline in constructive communication (Birditt, Brown, Orbuch, \& McIlvane, 2010). Unhealthy communication and interaction is the wellspring of many family dysfunctions (Sharif et al., 2013). Emotional divorce drives individuals off into lesser communication. Couples already feel the distance between them, and decide that they will be better off on their own. The little communication that exists is dysfunctional and immature; quarrels, insults, and disrespect are pervasive.

One of the areas of focus in ISTDP is improving clients' emotional connection with significant others (Abbass, Sheldon, Gyra, \& Kalpin, 2008) and restructuring their attachment styles (Abbass, Town, \& Driessen, 2012). The structure of emotional connectedness, known to ISTDP as internal objects relations, refers to self-representations in interaction with a significant other's representation during an infant's grandiose exhilaration. These emotional structures of the memory play an important role in the development of the primary cognitive motivational system which navigates a person's effort for closeness, maintenance or increasing possibilities of positive emotional states and reducing, avoiding or escaping negative states (Jarareh \& Talepasand, 2011). As transactions develop, a sense of gaining more knowledge about another person's view of one and acknowledging that knowledge develops with it; individuals gain a common ground of understanding themselves, and as a person interacting with others in mutual relationships (Miller, 2008).

By increasing spouses' understanding of each other in a marriage, especially by bringing the mutual nature of the relationship under attention, through focusing on and promoting empathy, calling attention for the influences that spouses leave on each other, as well as zooming in on partner's feelings and thoughts, ISTDP helps increase interpersonal processing (Reid et al., 2008). Increased interpersonal processing helps couples develop a metacognitive awareness of ways of interacting with one another about common experiences (Sharif et al., 2013). Couples' marital conflicts will decrease considerably as they gain interpersonal processing and acquire more competence and control in encountering negative emotions (Dew, 2008).

Conflicts and a failure of interpersonal processing as a result of emotional divorce, lead to anxiety, rage, aggression, and despair among individuals. Once these emotions are activated by concurrent stressful events, anxiety and defenses are awakened. The result is a blend of anxiety, somatization, depression, avoidance, self-defeating patterns, and interpersonal problems. ISTDP helps clients figure how to encounter emotions and/or conflicts to resolve their problems (Russell et al., 2016), express and experience their negative, avoided feelings (rage, aggression, fear, stress, anguish, and despair) developed during emotional divorce (Davanloo, 1999). ISTDP's basic assumption of mental problems is that mental disorders, which are clinical pictures of people in emotional, mental distress, are representations of underlying pathological cognitive structures. Hence, approaches which transform mental and psychological structures lead to changes in mental distress and pathological features of individuals' personality (Russell et al., 2016).

Concluding from the findings of the present study, and to reduce marital conflicts and increase married women's interpersonal processing, ISTDP is recommended. These findings 
provide valuable information for counselors and family therapists. Along with the results, the current study has been accompanied by limitations that the barriers related to gathering data tool and the study sample are the most important of these limitations. The target population was one of the limitations of the study, which solely examined married women with emotional divorce. We recommend that similar studies be carried out on both genders to co-evaluate them, and therefore generalize the findings. Moreover, the self report questionnaires were used to collect data; hence its results should be interpreted with caution.

Conflict of Interest: The authors declare that they have no competing interests.

Acknowledgments: We would like to express our gratitude to the participants, and others who cooperated with us in carrying out the study.

\section{References}

Abbass, A., Sheldon, A., Gyra, J., \& Kalpin, A. (2008). Intensive short-term dynamic psychotherapy for DSM-IV personality disorders: A randomized controlled trial. The Journal of nervous and mental disease, 196(3), 211-216.

Abbass, A., Town, J., \& Driessen, E. (2012). Intensive short-term dynamic psychotherapy: a systematic review and meta-analysis of outcome research. Harvard review of psychiatry, 20(2), 97-108.

Bahari, F., Fatehizadeh, M., Ahmadi, A., Molavi, H., \& Bahrami, F. (2010). The effect of hope, forgiveness and combined marital counseling on interpersonal cognitive distortions of divorcing couples. Journal of Research in Behavioural Sciences, 8(1), 25-33.

Birditt, K. S., Brown, E., Orbuch, T. L., \& McIlvane, J. M. (2010). Marital conflict behaviors and implications for divorce over 16 years. Journal of Marriage and Family, 72(5), 1188-1204.

Davanloo, H. (1999). Intensive short-term dynamic psychotherapy-central dynamic sequence: head-on collision with resistance. International Journal of Intensive Short-Term Dynamic Psychotherapy, 13(4), 263-282.

Dew, J. (2008). Debt change and marital satisfaction change in recently married couples. Family Relations, 57(1), 60-71.

Faramarzi, M., Azadfallah, P., Rasoolzadeh-Tabatabai, K., \& Shokry-Shirvani, J. (2012). The Effect of Brief Core Conflictual Relationship Theme (CCRT) Psychoanalytic Psychotherapy in Improvement of Gastrointestinal Symptoms and Conflict Resolution Styles in Patients with Functional Dyspepsia. Journal of Clinical Psychology, 3(4), 1-13.

Frederickson, J. J., Messina, I., \& Grecucci, A. (2018). Dysregulated anxiety and dysregulating defenses: Toward an emotion regulation informed dynamic psychotherapy. Frontiers in psychology, 9.

Ghorbani, N., Watson, P., Sarmast, Z., \& Chen, Z. J. (2018). Post-Critical Beliefs and religious reflection: Religious Openness Hypothesis in Iranian university and Islamic seminary students. Journal of Empirical Theology, 31(1), 49-70.

Gottman, J. M. (2008). Gottman method couple therapy. Clinical handbook of couple therapy, 4(8), 138-164. 
Haidari, S., \& Alahyari, A. (2012). An Investigation into the Effect of Short-Term Psychoanalytic Psychotherapy with Self-Psychology Approach on Change of Attachment Style in Students with Insecure Attachment. Counseling Culture and Psychotherapy, 3(10), 33-49.

Haratian, A. A., Janbozorgi, M., \& Agah, H. M. (2015). The role of early maladaptive schemas and religiosity in predicting matrimony conflict of married women. Islamic Journal of Women and The Family, 3(4), 45-62.

Hashemi, L., \& Homayuni, H. (2017). Emotional Divorce: Child's Well-Being. Journal of Divorce \& Remarriage, 58(8), 631-644.

Haviland, W. A., Prins, H. E., McBride, B., \& Walrath, D. (2013). Cultural anthropology: The human challenge: Cengage Learning.

Jarareh, J., \& Talepasand, S. (2011). The Effects of Management of Tactical Defenses in Intensive Short-term Dynamic Psychotherapy on Couple's Satisfaction. Journal of Clinical Psychology, 2(10), 13.

Kaslow, F. W. (2010). A family therapy narrative. The American Journal of Family Therapy, $38(1), 50-62$.

Khorianian, M., Heidari, N. L., Tabibi, Z., \& Aghamohammadian, S. H. (2013). Effectiveness of Intensive Short-Term Dynamic Psychotherapy in Decreasing the Symptoms of Depression and Increasing Emotional Disclosure in Patients Suffering from Depression. Journal of Clinical Psychology, 7(26), 37-46.

Lalzadeh, E., Asghari Ebrahimabad, M., \& Hesarsorkhi, R. (2015). The Investigation of Role of Early Maladaptive Schemas in Predicting Emotional Divorce. Journal of Clinical Psychology, 7(2), 101-108. doi:10.22075/jcp.2017.2203

Miller, S. (2008). Thinking and speaking in the third person: an extraction study of a technique from systemic-constructivist couple therapy. Graduate program in psychology. York University.

Naderi Nobandegani, Z. (2015). Effectiveness of systemic-constructivist Couple therapy on interpersonal processing, mutuality, relationship closeness and dyadic adjustment in distressed couple. (Phd), Shahid Chamran University Of Ahvaz, Ahvaz.

Rahmani, F., Salehi, M., \& Rezae, F. (2009). Treating generalized anxiety disorder using pharmacological and psychodynamic approaches of therapy. Journal of Iranian Psychologists.

Reid, D. W., Dalton, E. J., Laderoute, K., Doell, F. K., \& Nguyen, T. (2006). Therapeutically induced changes in couple identity: The role of we-ness and interpersonal processing in relationship satisfaction. Genetic, social, and general psychology monographs, 132(3), 241284.

Reid, D. W., Doell, F. K., Dalton, E. J., \& Ahmad, S. (2008). Systemic-constructivist couple therapy (SCCT): Description of approach, theoretical advances, and published longitudinal evidence. Psychotherapy: Theory, Research, Practice, Training, 45(4), 477.

Russell, L. A., Abbass, A. A., Allder, S. J., Kisely, S., Pohlmann-Eden, B., \& Town, J. M. (2016). A pilot study of reduction in healthcare costs following the application of intensive short-term dynamic psychotherapy for psychogenic nonepileptic seizures. Epilepsy \& Behavior, 63, 17-19. 
Sahebihagh, M. H., Khorshidi, Z., Atri, S. B., \& Jafarabadi, M. A. (2017). Investigating the relationship between self-efficacy and emotional divorce among nurses in the city of Rasht, Iran (2015). Annals of Tropical Medicine and Public Health, 10(6), 1596.

Sanaei, B., \& Barati, T. (2000). Family and marriage assessment scales. Tehran: Beesat.

Sharif, F., Soleimani, S., Mani, A., \& Keshavarzi, S. (2013). The effect of conflict resolution training on marital satisfaction in couples referring to counseling centers in Shiraz, southern Iran. International Journal of Community Based Nursing \& Midwifery, 1(1), 26-34.

Statistical Center of Iran. (2012). The Statistical Yearbook of Iran Retrieved from https://www.amar.org.ir/english 